pollen season. Outdoor workers should be informed; training should be addressed in order to promote collective and individual control and preventive measures. Being the Mediterranean area subject to thunderstorm episodes it is necessary the activation to specific planning to respond at these events.

\section{NETWORKS FOR POLLEN AND FUNGAL SPORES MONITORING: INTEGRATED APPROACH TO SUPPORT HEALTH SURVEILLANCE WITH REGARD TO OCCUPATIONAL ALLERGIES IN ITALY}

\begin{abstract}
${ }^{1} \mathrm{MC}$ D'Ovidio*, ${ }^{2} \mathrm{~F}$ de' Donato, ${ }^{3} \mathrm{R}$ Ariano, ${ }^{4,5} \mathrm{M}$ Bonini, ${ }^{3} \mathrm{G}$ Moscato, ${ }^{6} \mathrm{~V}$ De Gironimo, ${ }^{1} \mathrm{~S} \mathrm{Di}$ Renzi, ${ }^{7} \mathrm{M}$ Bonafede, ${ }^{1} \mathrm{C}$ Grandi, ${ }^{7} \mathrm{~A}$ Marinaccio, ${ }^{2} \mathrm{P}$ Michelozzi. 'National Workers' Compensation Authority (INAIL), Department of Occupational and Environmental Medicine, Epidemiology and Hygiene, Monte Porzio Catone (Rome), Italy; ${ }^{2}$ Department of Epidemiology Lazio Regional Health Service, ASL Roma 1, Rome, Italy; ${ }^{3}$ Association of Italian Immunologists, Outpatient and Hospital Allergists (A.A.I.I.T.O.), Florence, Italy; ${ }^{4}$ Department of Medical Prevention, Agenzia di Tutela della Salute della Città Metropolitana di Milano, Parabiago (Milan) Italy; ${ }^{5}$ Italian Monitoring Network in Aerobiology of the Italian Association of Aerobiology (A.I.A.- R.IIM.A. ${ }^{\circledR}$ ), Parabiago (Milan), Italy; ${ }^{6}$ POLLnet Network, Italian National Institute for Environmental Protection and Research (ISPRA), Rome, Italy; ${ }^{7}$ National Workers' Compensation Authority (INAIL), Department of Occupational and Environmental Medicine, Epidemiology and Hygiene, Rome, Italy
\end{abstract}

\subsection{6/oemed-2018-ICOHabstracts.1083}

Introduction The purpose of national and international aerobiological networks is the monitoring of pollen and fungal spores in defined geographical areas, followed by the spreading of data regarding several seasonal species by the use of the bulletins and calendars. These data are usually available on line. Our proposal focuses on the integration of exposure data with health surveillance systems (ER visits and hospital admissions) and health surveillance practices in workers occupationally exposed to aeroallergens.

Methods Within an Italian project funded by the Ministry of Health, the monitoring of environmental exposures, including pollen in relation to health outcomes is being set up to evaluate the effects and set up surveillance and prevention measures. For the major Italian cities, pollen data from the different monitoring networks and health outcome data to set up a rapid surveillance system with weekly updates on the potential health effects of pollen and fungal spores among vulnerable groups such as people suffering from allergies and respiratory conditions, children, workers etc.

Results The results will help provide a rapid monitoring on the health effects of pollen exposure in 2017 in Italy. Specific focus will be on occupational exposure and subjects with asthma and allergic rhinitis. These findings will also serve as a basis for the setting up of specific epidemiological studies to increase the evidence on health risks and develop adequate prevention measures.

Conclusion The optimisation of environmental and health data acquisition is of crucial importance for a proper analysis of trends regarding health outcomes in a number of subjects employed in different job sectors and with different job titles. Networks of data provided by several institutions may facilitate a better understanding of the results of epidemiological studies on occupational allergies, allowing a better study design in the case of both general populations and workers exposed to aeroallergens.
1177 HOME-OFFICE: NEW CHALLENGES FOR OCCUPATIONAL HEALTH AND SAFETY

${ }^{1}$ C Esteban*, ${ }^{1}$ CA Fiori, ${ }^{2}$ PA Ramadan, ${ }^{1}$ EC Sá, ${ }^{1} \mathrm{MJ}$ Gimenez. ${ }^{1} \mathrm{ABC}$ Medical School Faculty, Santo André, Brazil; ${ }^{2}$ University of São Paulo, São Paulo, Brazil

\subsection{6/oemed-2018-ICOHabstracts. 1084}

Introduction The domestic office is a new and constantly growing labour organisation in Brazil and the world, especially in the tertiary or service sector. In 2011, the Brazilian Law began to recognise the existence of telework, which represented an important step in regulating this new type of work. However, it is still very difficult to define what characterises remote work and to guarantee the labour rights provided for in the law on health and safety at work. The objective of this study was to review the contents of health and safety in the field of teleworking and the current regulatory norms.

Methods Bibliografic review at Pubmed, LILACS and MEDLINE databases, using the key-words 'home-office', 'workorganization' and 'labour law', in the interval of 1980 to 2016.

Results Home office work has many good points: inclusion of people with disabilities, reduction of operational costs and bureaucratic expenses by the employer, self-determination of working time and the reduction of travel time by the employee. Nowadays, the labour rights of those who perform their work at a distance are the same as those who go to the company headquarters, which will be responsible for occupational diseases and even accidents.

Conclusion The courts maintained a conservative view of homeoffice work in Brazil. In theory, this type of work must follow the labour law of formal work, being responsible for occupational diseases and even accidents. However, the big question is how to put all these guidelines into practice, how to supervise the duties of employers and employees, and how to guarantee labour rights, such as work accidents. Therefore, it is necessary to deepen our studies on the subject and make it legally established.

\section{HEALTH EFFECTS FROM HAND-ARM VIBRATIONS IN SWEDISH MECHANICAL INDUSTRY}

Per Vihlborg, Ing-Liss Bryngelsson, Louise Fornander, Pål Graff. Department of Occupational and Environmental Medicine, Örebro University Hospital

\subsection{6/oemed-2018-ICOHabstracts. 1085}

Background Working with handheld vibrating tools is common in the mechanical industry and one of the main causes of occupational disease in Sweden. There are several well-known effects on vascular, neurological and musculoskeletal symptoms in the hands from vibrations.

Methods This report is based on medical examinations performed on 38 males at a mechanical industry. The medical examination consisted of questionnaires regarding symptoms and exposure, standardised medical examination and quantitative sensory testing (QST). The exposure to hand-arm vibrations was also measured. Blood samples were collected to investigate for biological markers for vibration exposure.

Results $24 \%$ of the exposed subjects had vascular symptoms in form of Raynaud's phenomenon, and 37\% had increased cold intolerance. More common was neurological symptoms which affected nearly $60 \%$ of the exposed subject. Although the 